\title{
Reply to "Laparoscopic Sleeve Gastrectomy in Patients with Ventricular Assist Devices, Beyond just Bridging to Heart Transplantation"
}

\author{
P. Van Aelst ${ }^{1}$ (D) $\cdot$ E. Deleus ${ }^{1} \cdot$ B. Van der Schueren ${ }^{2} \cdot$ B. Meyns ${ }^{3} \cdot$ K. Vandersmissen $^{3} \cdot$ M. Lannoo ${ }^{1}$
}

Received: 29 September 2020 / Revised: 30 September 2020 / Accepted: 30 September 2020 / Published online: 15 October 2020

(C) Springer Science+Business Media, LLC, part of Springer Nature 2020

We read with interest the comments made to our paper "Laparoscopic Sleeve Gastrectomy in Patients with Ventricular Assist Devices, Beyond just Bridging to Heart Transplantation." We agree with the comments made and appreciate the statement that weight loss could contribute to myocardial recovery. An observation that we could not make on our local limited experience. The authors state, correctly, that the challenge of small sample size can be addressed with a prospective multicenter registry. Especially as the role of weight evolution in heart failure patients is complex. Some patients suffer from cardiac cachexia and gain weight after LVAD implantation as part of an improvement of their general condition. Patients with chronic heart failure, rather than those with acute failure, seem to be at risk to develop overweight. It is intuitive that lifestyle conditions and exercise capacity are likely to play an important role in the development of obesity in chronic heart failure patients after LVAD implantation. As such, it is logical to add these parameters as well to the registry as it opens the possibility to act preventively on the development of obesity.

\section{Compliance with Ethical Standards}

Conflict of Interest The authors declare that they have no conflict of interest.

Publisher's Note Springer Nature remains neutral with regard to jurisdictional claims in published maps and institutional affiliations.

P. Van Aelst

pieter.vanaelst@uzleuven.be

E. Deleus

ellen.deleus@uzleuven.be

B. Van der Schueren

bart.vanderschueren@uzleuven.be

B. Meyns

bart.meyns@uzleuven.be

K. Vandersmissen

katrien.vandersmissen@uzleuven.be

M. Lannoo

matthias.lannoo@uzleuven.be

1 Department of Abdominal Surgery, University Hospitals Leuven, Leuven, Belgium

2 Department of Endocrinology, University Hospitals Leuven, Leuven, Belgium

3 Department of Clinical Cardiac Surgery, University Hospitals Leuven, Leuven, Belgium 